\title{
PRODUÇÃO DE ÁCIDOS GRAXOS VOLÁTEIS POR FERMENTAÇÃO ANAERÓBIA DE MANIPUEIRA E DE PERMEADO DE SORO DE QUEIJO
}

\author{
Denise Aparecida Zempulski ${ }^{1}$ \\ Karen Andressa Pelle Viar ${ }^{1}$ \\ Larissa Delallo Martins Lampa ${ }^{I}$ \\ Josiane Peternela ${ }^{1}$ \\ Camila de Oliveira Cardoso ${ }^{1}$ \\ Mônica Lady Fiorese ${ }^{1}$ \\ Salah Din Mahmud Hasan ${ }^{1}$
}

\begin{abstract}
Resumo: A aplicação de resíduos da agroindústria como substratos em processos fermentativos para a obtenção de compostos de interesse comercial tem sido foco de muitos estudos, o que também contribui para solucionar o problema da poluição nos processos de agroindustrialização. O objetivo deste trabalho é o estudo da biodigestão anaeróbia da manipueira e do permeado de soro de queijo para fins de produção de ácidos graxos voláteis (AGVs). As fermentações foram conduzidas a $30^{\circ} \mathrm{C}$, sob agitação, utilizando como inoculo o lodo proveniente de biodigestor em funcionamento de tratamento de dejeto suíno. Foram feitos testes de fermentação escura (na ausência de luminosidade). Para a manipueira, as concentrações de 29,0 g. $\mathrm{L}^{-1}$ de açúcares redutores e 3,2 g. $\mathrm{L}^{-1}$ de alcalinidade em bicarbonato resultaram em maior produtividade de AGV (0,0184 mg AGV por mg de DQO por h). Para o permeado de soro de queijo, o mesmo já contém 150 g. $\mathrm{L}^{-1}$ de açúcares redutores, sem suplementação de fonte de carbono e, portanto foi diluído para se obter níveis de 50 e 90 g. $\mathrm{L}^{-1}$ de açúcares redutores. Dessa forma, os melhores resultados de AGV foram obtidos com 90 g. $\mathrm{L}^{-1}$ de açúcares redutores e 10,26 g. $\mathrm{L}^{-1}$ de alcalinidade em bicarbonato, resultando em produtividade de $0,0011 \mathrm{mg}$ de AGV por mg de DQO por h. O uso da manipueira e também do permeado de soro de queijo na biodigestão anaeróbica apresentam boa possibilidade de realocação dos resíduos e agregação de valor.
\end{abstract}

Palavras-chave: manipueira, permeado de soro de queijo, biodigestão anaeróbia, fermentação.

Abstract: The application of agro-industrial residues as substrates for fermentation
processes for obtaining compounds of commercial interest has been the focus of many
studies, which also helps to solve the problem of pollution in the process of
industrialization. The aim of this work is to study biodigestion process of manipueira and
cheese whey permeate for means of volatile fatty acids (VFAs) production. The
fermentations processes were performed at $30^{\circ} \mathrm{C}$, under agitation, and the seed sludge used
for the acidogenic fermentation was collected from a local anaerobic digester used for
swine manure treatment. The dark fermentation (absence of light) was accomplished. For
cassava wastewater, concentrations of $29 \mathrm{~g} . \mathrm{L}^{-1}$ of reducing sugars and $3.2 \mathrm{gL}^{-1}$ of alkalinity
resulted in greater productivity of VFAs $(0.0184 \mathrm{mg}$ VFA per mg COD per h). For the
cheese whey permeate, it already contains $150 \mathrm{~g} . \mathrm{L}^{-1}$ of glucose (reducing sugar) without
supplemental carbon source, and thus was diluted to obtain levels of 50,90 and $150 \mathrm{~g} . \mathrm{L}^{-1}$
of reducing sugars. Thus best results obtained for AGV were with $90 \mathrm{~g} . \mathrm{L}^{-1}$ of reducing
sugars and $10.26 \mathrm{~g} . \mathrm{L}^{-1}$ of alkalinity, resulting in productivity of $0.0011 \mathrm{mg} \cdot \mathrm{L}^{-1}$ of $\mathrm{AGVs}$

${ }^{1}$ Universidade Estadual do Oeste do Paraná - UNIOESTE. E-mail: denise.zempulski@gmail.com

ENGEVISTA, V. 16, n. 4, p. 431-447, Dezembro 2014 
per mg COD per $\mathrm{h}$. The use of cassava and also cheese whey permeate in anaerobic digestion exhibit good possibility of reallocation of waste with added-value.

Keywords: manipueira, cheese whey permeate, anaerobic digestion, fermentation

\section{INTRODUÇÃO}

A mandioca é uma cultura amplamente difundida por todo $\mathrm{o}$ território nacional, sendo mais comum no sul-sudeste do país (Cereda, 2001). Um resíduo importante no processo de extração de fécula de mandioca é o farelo, massa ou bagaço, caracterizado como material fibroso da raiz, contendo parte da fécula que não foi possível extrair no processamento. A elevada quantia de farelo gerado e a sua umidade fazem com que este material se apresente como um problema durante a safra, devido às dificuldades de transporte $\mathrm{e}$ armazenamento (Leonel, 2001). Dentre os resíduos líquidos do processamento da mandioca, cita-se a manipueira a qual caracteriza a água de constituição da raiz, extraída na prensagem da massa ralada, na confecção da farinha (Barana \& Cereda, 2000). Segundo Sun et al. (2012), uma fecularia pode gerar de 20 a $60 \mathrm{~m}^{3}$ de manipueira por tonelada de mandioca processada, sendo este o resíduo mais problemático por possuir elevada carga poluente, com altos valores de demanda química de oxigênio (DQO de 10496 mg. $\mathrm{L}^{-1}$ ) e de demanda bioquímica de oxigênio (DBO de 6300 $\mathrm{mg} . \mathrm{L}^{-1}$ ), além de potencial tóxico devido à presença de cianeto $\left(2,3 \mathrm{mg} \cdot \mathrm{L}^{-1}\right)$.

Outros resíduos de grande impacto ambiental quando descartados incorretamente, são os resíduos de indústrias de laticínio. $\mathrm{O}$ fracionamento dos constituintes do leite por ultrafiltração resulta em derivados de grande valor nutricional e comercial, como o retentado (fração concentrada composta por proteínas e gordura) e o permeado (fração diluída composta por lactose, sais minerais, eletrólitos, compostos nitrogenados e água) (Oliveira et al., 2006). O permeado de soro de queijo ultrafiltrado é uma fonte de macrominerais e eletrólitos como cálcio $\left(\mathrm{Ca}^{++}\right)$, magnésio $\left(\mathrm{Mg}^{++}\right)$, cloro $\left(\mathrm{Cl}^{-}\right)$, sódio $\left(\mathrm{Na}^{+}\right)$e potássio $\left(\mathrm{K}^{+}\right)$, necessários ao equilíbrio osmótico das células animais. Além de apresentar teores consideráveis de lactose e vitaminas do complexo B (ex.: riboflavina), contém proteínas de alto valor biológico (Mahan, 1998).

O interesse pela aplicação da digestão anaeróbia é evidenciado pelos inúmeros trabalhos publicados na literatura pertinente (Lee et al, 2014, Sun et al., 2012, Correia \& Del Bianchi, 2008, Mohan et al., 2007). Este interesse se deve em grande parte à crise energética devido ao aumento do preço dos combustíveis fósseis, conjunto com o aumento da demanda por energia, e também ao desenvolvimento de uma consciência ambiental além do desenvolvimento de modelos de biodigestores mais avançados e mais eficientes. Esses aspectos permitiram o uso mais amplo desse tipo de tratamento, englobando agora não somente resíduos urbanos e rurais, mas também da agroindústria (Braun et al., 2010), onde a digestão anaeróbia destaca-se devido as suas diversas características favoráveis, como baixa produção de sólidos; baixo consumo de energia, baixos custos de implementação, manutenção e operação, tolerância a elevadas cargas orgânicas e degradação de certos compostos tóxicos (Oliveira, 2007).

Por outro lado os principais problemas da digestão anaeróbia são (Braber, 1995): a natureza (composição) dos resíduos pode variar dependendo da localização (zona de geração) e da estação do ano; mistura ineficiente do resíduo e lodo de esgoto pode afetar a eficiência do processo; podem ocorrer obstruções de canalização por pedaços maiores de resíduos, principalmente em sistemas contínuos. 
O tratamento anaeróbio de substratos hidrolisados envolve processos metabólicos complexos, que ocorrem em etapas sequenciais (acidogênese, acetogênese e metanogênese) e que dependem da atividade de microorganismos distintos. O controle da etapa de acidogênese é essencial pois é nesta fase que ocorre o acúmulo de AGVs ácidos graxos voláteis (ácidos acético, propiônico, butírico, etc.) devendo-se portanto minimizar a evolução do processo para a metanogênese onde ocorre o consumo dos ácidos e produção do biogás. O máximo acúmulo dos ácidos graxos voláteis - AGVs - pode representar relevante interesse, pois são compostos intermediários importantes em processos de polimerização como no caso da produção dos PHAs polihidroxialcanoatos, os chamados bioplásticos. Assim, o objetivo deste trabalho é o estudo da biodigestão anaeróbia da manipueira e do permeado de soro de queijo usados como substratos para fins de produção e recuperação de AGVs.

\section{MATERIAIS E MÉTODOS}

\subsection{INÓCULO}

O inoculo usado foi o lodo de biodigestor em funcionamento utilizado para tratamento de dejeto suíno. Não foi realizada a operação de adaptação do inoculo ao substrato. $\mathrm{O}$ inoculo foi padronizado em termos de sólidos totais e sólidos totais voláteis (Apha, 1998). Obteve-se os valores médios de $0,18 \%$ para sólidos totais (ST) e $0,09 \%$ para sólidos totais voláteis (STV). Todos os experimentos foram conduzidos na mesma concentração de inoculo, ou seja, utilizando $25 \%$ de volume de dejeto (com $0,18 \%$ de ST) para volume final de $2 \mathrm{~L}$ de meio.

\subsection{MEIOS DE CULTIVO}

Foram testados inicialmente
quatro diferentes meios de cultivo visando a produção de AGVs: a manipueira, o hidrolisado amiláceo, o permeado de soro de queijo e o meio sintético (padrão). A manipueira foi coletada em uma indústria (fecularia) e caracterizada em termos de demanda química de oxigênio (DQO), demanda bioquímica de oxigênio (DBO), nitrogênio total, fosfato total, alcalinidade em bicarbonato, oxigênio dissolvido, sólidos totais, sólidos totais voláteis, açúcar redutor, $\mathrm{pH}$ e acidez, seguindo as referências citadas no item 2.5.

O hidrolisado amiláceo foi obtido mediante hidrolise ácida do amido presente no bagaço da mandioca. $\mathrm{O}$ bagaço da mandioca foi coletado na mesma indústria fornecedora da manipueira. A hidrólise do bagaço da mandioca baseou-se nos estudos de Krueger (2009), onde foram testados parâmetros para a obtenção de maior quantidade de glicose liberada na hidrólise ácida do bagaço da mandioca. Dessa forma, os experimentos ocorreram adicionando a um erlenmeyer $10 \mathrm{~g}$ de bagaço de mandioca, $100 \mathrm{~mL}$ de manipueira e $10 \mathrm{~mL}$ de solução de ácido clorídrico $10 \%$ (v/v), em triplicata, e mantidos em autoclave, numa temperatura de $121^{\circ} \mathrm{C}$ por $30 \mathrm{~min}$, obtendo-se assim o hidrolisado amiláceo usado nos experimentos, que foi caracterizado em termos de açúcares redutores, conforme Miller (1959).

O permeado do soro de queijo foi cedido por uma indústria que processa como matéria prima o soro de leite, e foi caracterizado em termos de demanda bioquímica de oxigênio (DBO), demanda bioquímica de oxigênio (DQO), fosfato total, cálcio, $\mathrm{pH}$, acidez, sólidos totais, cinzas, lactose e proteína.

Para os meios de cultivo testados foram adicionados os constituintes baseados nos estudos de FernándezMoralez et al. (2010), em que os autores objetivavam a produção de AGVs, e hidrogênio usando como substrato um meio sintético. Os componentes utilizados e suas respectivas quantidades estão apresentados na Tabela 1. A quantidade de glicose (açúcares 
redutores) adicionada variou conforme o experimento e a concentração existente nos substratos usados (manipueira, permeado e hidrolisado amiláceo). $\mathrm{O}$ meio sintético (padrão), para fins de controle, foi preparado com água destilada e adicionando os constituintes.

Tabela 1- Constituintes e quantidades dos meios de cultivo

\begin{tabular}{lc}
\hline Componente & $\begin{array}{c}\text { Concentração } \\
\left(\text { g. } \mathbf{L}^{-\mathbf{1}}\right)\end{array}$ \\
\hline $\mathrm{Glicose}$ & 14,59 \\
$\left(\mathrm{NH}_{4}\right) \mathrm{Cl}$ & 4,89 \\
$\mathrm{KH}_{2} \mathrm{PO}_{4}$ & 2,85 \\
$\mathrm{NaCl}$ & 1,07 \\
$\mathrm{Na}_{2} \mathrm{SO}_{4}$ & 0,21 \\
$\mathrm{MgCl}_{2} 6 \mathrm{H}_{2} \mathrm{O}$ & 0,44 \\
$\mathrm{EDTA}_{2}$ & 0,18 \\
$\mathrm{ZnSO}_{4} \cdot 7 \mathrm{H}_{2} \mathrm{O}$ & $11,7.10^{-3}$ \\
$\mathrm{FeSO}_{4} \cdot 7 \mathrm{H}_{2} \mathrm{O}$ & $11,3 \cdot 10^{-3}$ \\
$\mathrm{MnCl}_{2} \cdot 4 \mathrm{H}_{2} \mathrm{O}$ & $9,1 \cdot 10^{-3}$ \\
$\mathrm{CuCl}_{2} 2 \mathrm{H}_{2} \mathrm{O}$ & $8,0.10^{-3}$ \\
$\mathrm{CoCl}_{2} \cdot 6 \mathrm{H}_{2} \mathrm{O}$ & $3,5 \cdot 10^{-3}$ \\
$\mathrm{CaCl}_{2}$ & $2,2.10^{-3}$ \\
$\mathrm{NiCl}_{2} \cdot 6 \mathrm{H}_{2} \mathrm{O}$ & $1,8 \cdot 10^{-3}$ \\
\hline
\end{tabular}

\subsection{FERMENTAÇÃO ANAERÓBIA}

Foram usados como reatores para os experimentos de biodigestão anaeróbia recipientes de vidro com capacidade de 3 L e tampa metálica. A Figura 1 mostra a montagem dos reatores tipo batelada para a biodigestão anaeróbia.

Em todos os experimentos, após dissolver os componentes da Tabela 1 com 2 L do meio de cultivo, foi adicionado o volume necessário de inoculo. A quantidade estabelecida de sólidos totais utilizados baseou-se nos estudos de Giongo (2011) e Lamaison (2009). Posteriormente o $\mathrm{pH}$ foi ajustado para 7,0 com solução de hidróxido de sódio $2 \mathrm{~N}$, sendo este procedimento necessário, pois segundo Correia \& Del Bianchi (2008), isto melhora na estabilização do processo fermentativo devido a manutenção do $\mathrm{pH}$ inicial no meio, pois valores iniciais muito baixos de $\mathrm{pH}$ acabam inibindo o processo.

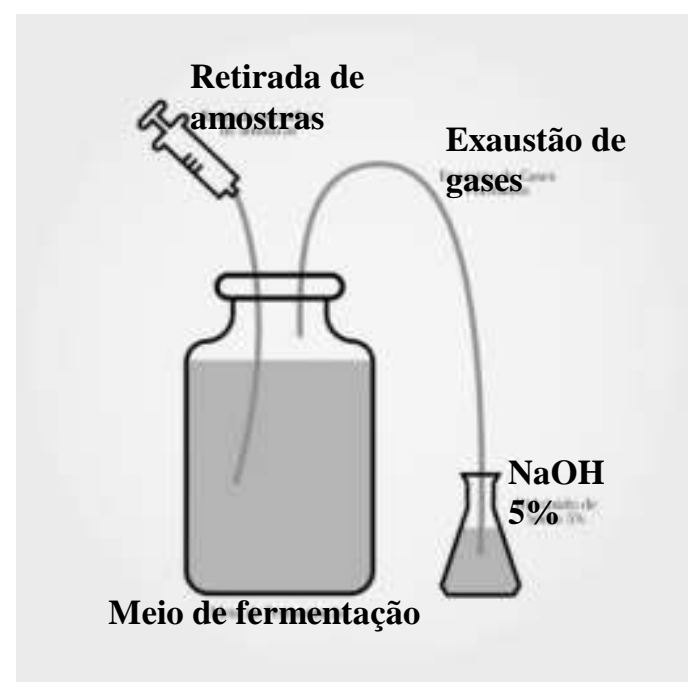

Figura 1- Esquema da fermentação e reatores utilizados

Os reatores foram tampados, e a mangueira de exaustão de gases foi acoplada a uma bomba de vácuo por 15 min com o intuito de retirada do ar presente no reator. Em seguida, essa mesma mangueira foi submersa no Erlenmeyer contendo hidróxido de sódio.

Todas as fermentações ocorreram em incubadora com agitação orbital (marca SOLAB, mod. SL-223) mantida a $30^{\circ} \mathrm{C}$ e sob agitação constante. Foram retirados $20 \mathrm{~mL}$ para análise de ácidos graxos voláteis (Buchauer, 1998). O volume total retirado de cada reator não excedeu $10 \%$ do volume total de meio de cultura, para não desestabilizar o processo. Inicialmente os ensaios tiveram como intuito verificar quais os meios de cultivo que geram os melhores resultados de produção (acúmulo) de AGVs.

Visando melhorar o processo de produção de AGVs, foi testada a fermentação anaeróbia na ausência de luminosidade, onde as demais condições operacionais foram mantidas. De acordo com Loss (2011), a fermentação para a produção de biohidrogênio e de ácidos orgânicos não depende da presença de luz. 


\subsection{AVALIAÇÃO DAS CONDIÇÕES OPERACIONAIS DO PROCESSO}

\subsubsection{MANIPUEIRA}

Usou-se um planejamento fatorial $2^{2}$ com quadruplicata no ponto central, totalizando 8 ensaios, onde foram testadas 3 níveis de concentrações de glicose e de bicarbonato de sódio (Tabela 2). Para a glicose foi considerada a concentração de açúcares redutores préexistente na manipueira. Os demais nutrientes foram adicionados conforme Tabela 1. Os valores entre parenteses na tabela referem-se aos valores reais aplicados de glicose.

Tabela 2- Matriz do planejamento fatorial $2^{2}$ com quadruplicata no ponto central.

\begin{tabular}{ccc}
\hline Ensaio & $\begin{array}{c}\mathbf{N a H C O}_{3} \\
\left(\text { g.L }^{-\mathbf{1}}\right)\end{array}$ & $\begin{array}{c}\text { Glicose } \\
(\text { g.L }\end{array}$ \\
\hline 1 & $-1(0,21)$ & $-1(9)$ \\
2 & $1(3,21)$ & $-1(9)$ \\
3 & $-1(0,21)$ & $1(29)$ \\
4 & $1(3,21)$ & $1(29)$ \\
5 & $0(1,71)$ & $0(19)$ \\
6 & $0(1,71)$ & $0(19)$ \\
7 & $0(1,71)$ & $0(19)$ \\
8 & $0(1,71)$ & $0(19)$ \\
\hline
\end{tabular}

Foi usado o programa STATISTICA $^{\mathrm{TM}}$ (v. 8.0, StatSoft, Inc.) para calcular os efeitos principais das variáveis e suas interações, bem como os dados relativos à análise de variância (ANOVA).

\subsubsection{PERMEADO DE SORO DE QUEIJO}

O permeado de soro de queijo contém em média 150 g. $\mathrm{L}^{-1}$ de lactose, o que corresponderia a 150 g. $\mathrm{L}^{-1}$ de açúcares redutores. Este valor corresponde quase a totalidade da DQO presente no permeado. Como a quantidade de açúcar (lactose) presente no permeado é elevada, 150 g.L $\mathrm{L}^{-1}$, decidiu-se fazer a biodigestão com o permeado in natura, e também diluindo-o para obter concentrações menores de açúcar redutor $\left(90\right.$ g.L $\mathrm{L}^{-1}$ e 50 g.L $\left.\mathrm{L}^{-1}\right)$. Foram testados também diferentes níveis de concentração de alcalinidade em bicarbonato, com a adição de bicarbonato de sódio $\left(0,0,44,1,50,2,56\right.$ e 3,00 g.L $\left.\mathrm{L}^{-1}\right)$ ao permeado, o qual já continha uma alcalinidade total de 7,7 g.L $\mathrm{L}^{-1}$ em bicarbonato.

\subsection{MÉTODOS ANALÍTICOS}

As análises de demanda química de oxigênio (DQO), sólidos totais (ST) e sólidos totais voláteis (STV) foram realizadas de acordo com Standard Methods for Examination of Water and Wastewater - Apha (1998). A determinação da concentração de açúcares redutores totais (AR) foi adaptado do método proposto por Miller (1959) sendo o resultado de açúcar redutor expresso como glicose. Para a análise de acidez, umidade e glicosídeos redutores seguiu-se conforme descrito nas Normas Analíticas do Instituto Adolfo Lutz (1985). A determinação de ácidos graxos voláteis (AGVs) foi feita conforme a metodologia proposta por Kapp (1984), descrita por Buchauer (1998), em que o volume de titulação até pH 4,3 é utilizado para fins de cálculo da alcalinidade em bicarbonato (Alc) e a diferença entre o volume de titulação de pH 5,0 a pH 4,0 é utilizado para calcular a concentração de ácidos graxos voláteis.

As análises de proteína foram realizadas empregando-se a metodologia descrita pelo Ministério da Agricultura, Pecuária e Abastecimento - MAPA, Brasil (2006). As análises de fostato total (FT) e nitrogênio total (NT) foram baseadas em Mackereth et al (1978) e o oxigênio dissolvido (OD) medido através de oxímetro (marca YSI, mod. Pro 10102030). As análises foram feitas em duplicata. 


\section{RESULTADOS E DISCUSSÃO}

\subsection{CARACTERIZACÃO DOS RESÍDUOS}

Para fins de comparação, na Tabela 3 constam os valores obtidos da caracterização da manipueira no presente trabalho, e de mais dois estudos, estes realizados por Giongo (2011) e Pastore (2010).

Tabela 3 - Caracterização da Manipueira

\begin{tabular}{|c|c|c|c|}
\hline \multirow[t]{2}{*}{ Parâmetros } & \multicolumn{3}{|c|}{ Referências } \\
\hline & anipueira & $\begin{array}{c}\text { Giongo } \\
\text { (2011) }\end{array}$ & $\begin{array}{c}\text { Pastore } \\
(2010)\end{array}$ \\
\hline DQO (mg. $\left.\mathrm{L}^{-1}\right)$ & 10300 & 8865 & 2250 \\
\hline NT (mg. $\left.\mathrm{L}^{-1}\right)$ & 67,2 & 116,48 & 105 \\
\hline $\mathrm{FT}\left(\mathrm{mg} \cdot \mathrm{L}^{-1}\right)$ & 21,84 & 26,86 & 0,83 \\
\hline Alc $\left(m g \cdot L^{-1}\right)$ & 213,43 & - & 330 \\
\hline $\mathrm{OD}\left(\mathrm{mg} \cdot \mathrm{L}^{-1}\right)$ & 2,35 & - & - \\
\hline S T $(\%)$ & 1,12 & 0,74 & - \\
\hline STV $(\%)$ & 1,03 & 0,67 & - \\
\hline $\operatorname{AR}\left(\mathrm{g} \cdot \mathrm{L}^{-1}\right)$ & 2,44 & 1 & - \\
\hline $\mathrm{pH}$ & 5,73 & 4,0 & 7,24 \\
\hline Acidez (\%) & 0,23 & 0,40 & - \\
\hline
\end{tabular}

Em ambos os trabalhos utilizou-se a manipueira: no primeiro objetivava a produção de AGVs e no segundo objetivava a produção de ácido cítrico. Nota-se que o valor obtido de DQO foi superior quando comparado aos estudos apresentados. Ao comparar o valor da concentração da matéria orgânica presente neste estudo com a concentração de um esgoto sanitário típico com DQO de aproximadamente $400 \quad \mathrm{mg} . \mathrm{L}^{-1}$ (Campos, 1994), pode-se observar o potencial poluidor da manipueira, fato agravado com o grande volume deste resíduo gerado pela indústria.

Quanto aos valores obtidos de nitrogênio total, este foi inferior ao encontrado nos outros dois estudos, e quanto ao fosfato obteve-se um valor próximo, porém inferior ao encontrado por Giongo (2011) e muito superior ao encontrado por Pastore (2010). A presença de nitrogênio e fósforo na manipueira a torna atrativa para uso como meio de cultivo de bactérias, devido a importância desses elementos no metabolismo desses micro-organismos. Os componentes, e respectivas quantidades presentes no resíduo podem variar devido a fatores como a idade da planta, tempo após a colheita, tipo e ajuste de equipamentos industriais (Cereda \& Mattos, 1996).

O hidrolisado amiláceo foi caracterizado em termos de açúcar redutor resultando em 80,4 g.L $\mathrm{L}^{-1}$. Krueger (2009) quantificou em seus estudos cerca de 10 g.L. L $^{-1}$ de açúcar redutor, após a hidrólise ácida do bagaço da mandioca com água, valor inferior ao encontrado neste estudo.

A hidrólise ácida do presente estudo foi realizada diretamente na manipueira. Todavia, na caracterização de açúcar redutor para a manipueira, obteve-se o valor médio de 2,44 g. $\mathrm{L}^{-1}$, sendo o bagaço da mandioca a principal fonte da alta concentração de açúcar redutor, evidenciando positivamente a utilização do bagaço da mandioca como fonte alternativa para o fornecimento de açúcares redutores no meio de cultivo de micro-organismos. É fundamental ressaltar que a composição da mandioca varia de um lugar para outro, e consequentemente, tal variação se estende também para seus resíduos.

Os valores obtidos na caracterização do permeado do soro de queijo encontram-se na Tabela 4. Como era de se esperar, pôde se verificar o elevado teor de DQO no permeado, bem como o de cálcio e de lactose (AR) devido ao fato do efluente ser oriundo do leite. Os valores de DQO e fosfato total são superiores aos encontrados na manipueira: o fosfato, cerca de 57 vezes maior, e DQO, cerca de 14 vezes. O valor de DQO corresponde a quantidade de açúcar redutor total presente no permeado na forma de lactose. 


\subsection{AVALIAÇÃO DE DIFERENTES SUBSTRATOS NA PRODUÇÃO DE AGVs}

Inicialmente foi feito um screening para se determinar os melhores meios de cultivo para a produção de AGVs, Os comportamentos de cada fermentação quanto a concentração de AGV acumulado podem ser observados na Figura 2. Todos os meios continham a mesma concentração de açúcares redutores $\left(14,59\right.$ g. $\left.\mathrm{L}^{-1}\right)$ seguindo a Tabela 1. Assim, foram adicionados 14,59 g. $\mathrm{L}^{-1}$ de glicose no meio sintético e, para a manipueira, a mesma foi complementada com glicose.

Tabela 4 - Caracterização do permeado do soro do queijo

\begin{tabular}{lc}
\hline Parâmetros & Quantidades \\
\hline DQO & $150000 \mathrm{mg} \cdot \mathrm{L}^{-1}$ \\
Fosfato total & $1246,9 \mathrm{mg} . \mathrm{L}^{-1}$ \\
Cálcio & $2024,04 \mathrm{mg} . \mathrm{L}^{-1}$ \\
$\mathrm{pH}$ & 6,6 \\
Acidez & $26^{\circ} \mathrm{D}$ \\
Sólidos totais & $15 \%$ \\
Cinzas & $0,82 \%$ \\
AR total & $150 \mathrm{~g} \cdot \mathrm{L}^{-1}$ \\
Alcalinidade & $7700 \mathrm{mg} . \mathrm{L}^{-1}$ \\
Proteína & $<0,18 \%$ \\
\hline
\end{tabular}

Para o hidrolisado amiláceo e o permeado foram necessárias diluições. Nota-se um pico de produção de AGVs para todos os meios testados. $\mathrm{O}$ experimento realizado com o permeado do soro de queijo como meio de cultivo apresentou maior acúmulo, obtendo um pico de 1986,0 mg.L em $35 \mathrm{~h}$ de fermentação. Comparando a biodigestão com a manipueira com a biodigestão com meio sintético (padrão) os picos foram próximos, sendo de $774,7 \mathrm{mg} . \mathrm{L}^{-1}$ de AGV em $23 \mathrm{~h}$ para o meio sintético, e 794,7 mg.L. $\mathrm{L}^{-1}$ de AGV em $23 \mathrm{~h}$ para o meio utilizando a manipueira. Já biodigestão realizada com o hidrolisado amiláceo obteve menor acúmulo de AGV, obtendo-se pico de $685,8 \mathrm{mg} . \mathrm{L}^{-1} \mathrm{de}$ AGVs em $35 \mathrm{~h}$.

Considerando a matéria orgânica (DQO) inicial presente no substrato, a conversão da mesma em AGVs no processo fermentativo é apresentada na Tabela 5 através das relações de $\mathrm{Y}=$ AGV/DQO (mg/mg) obtidas nos picos de produção para cada meio de cultivo testado, bem como a produtividade $\mathrm{P}$ (mg/mg.h) obtida se fosse considerado o tempo (t) em que o pico foi obtido.

Tabela 5 - Conversão (Y) e produtividade $(\mathrm{P})$ da fermentação.

\begin{tabular}{lccc}
\hline Meio & $\begin{array}{c}\text { Pico de } \\
\text { AGV } \\
\text { (tempo) }\end{array}$ & $\begin{array}{c}\text { Conv. (Y) } \\
\text { AGV/DQO } \\
(\mathrm{mg} / \mathrm{mg})\end{array}$ & $\begin{array}{c}\text { Produt. (P) } \\
\text { AGV/DQO.t } \\
(\mathrm{mg} / \mathrm{mg} . \mathrm{h})\end{array}$ \\
\hline $\begin{array}{l}\text { Perm. } \\
\text { Soro }\end{array}$ & $\begin{array}{c}1986,0 \\
(35 \mathrm{~h})\end{array}$ & 0,013 & 0,00038 \\
\hline Manip. & $\begin{array}{c}794,7 \\
(23 \mathrm{~h})\end{array}$ & 0,077 & 0,0033 \\
\hline $\begin{array}{l}\text { Hidrol. } \\
\text { amil. }\end{array}$ & $\begin{array}{c}685,8 \\
(35 \mathrm{~h})\end{array}$ & 0,0085 & 0,00024 \\
\hline $\begin{array}{l}\text { Meio } \\
\text { sint. }\end{array}$ & $\begin{array}{c}774,7 \\
(23 \mathrm{~h})\end{array}$ & 0,053 & 0,0023 \\
\hline
\end{tabular}

Apesar do pico mais elevado de AGV obtido com permeado de soro de queijo, verifica-se que a manipueira apresenta uma maior conversão da DQO em AGVs e consequentemente maior produtividade. Isso se deve ao menor teor de DQO da manipueira e o fato do pico ter sido obtido em um menor tempo.

O permeado de soro de queijo é fonte de sais minerais, compostos nitrogenados, eletrólitos, água e principalmente lactose (15\%). Assim, acredita-se que esses constituintes, além da DQO elevada, também podem ter contribuído para a alta produção de AGVs. Em pesquisas realizadas por Bronstein \& Monte Alegre (1998) onde o permeado de soro de queijo foi utilizado como substrato para o crescimento de fermento, em especial Lactococcus Lactis Subsp. Lactis, suplementado com extrato de levedura e peptona, a utilização do mesmo foi considerada viável. 


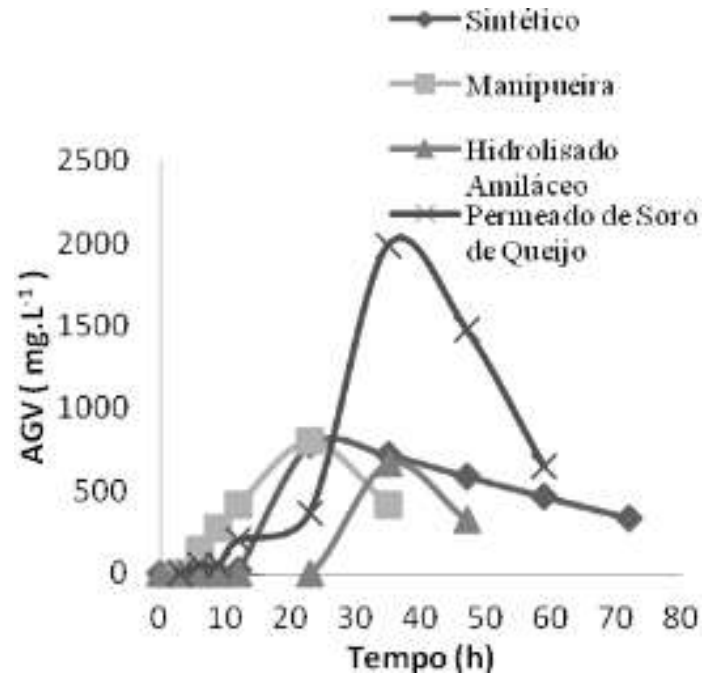

Figura 2 - Comparação do perfil cinético da produção de AGV com diferentes meios de cultivo, todos com a mesma concentração de açúcares redutores $\left(14,59 \mathrm{~g} . \mathrm{L}^{-1}\right)$.

Foi observado por Mohan et al. (2007), que a melhor atividade das bactérias acidogênicas ocorreu no decréscimo de $\mathrm{pH} 6$ para 4,5, onde foi utilizado como substrato águas residuais de indústria de lacticínios com microflora anaeróbia mista à temperatura de $28^{\circ} \mathrm{C}$. Nessas condições obtiveram a máxima produção de $3000 \mathrm{mg} . \mathrm{L}^{-1}$ de AGVs, considerando que foi usado um efluente com DQO de 10400 mg.L ${ }^{-1}$.

\subsection{FERMENTAÇÃO ESCURA}

As Figuras 3 e 4 apresentam a comparação entre as fermentações com e sem ausência de luz, para a manipueira e para o permeado, respectivamente. Conforme a Figura 3 verifica-se que na fermentação da manipueira com ausência de luz ocorreu uma maior produção de AGVs (pico de 1095 mg.L $\mathrm{L}^{-1}$, em $21 \mathrm{~h}$ ) em comparação com a fermentação com a manipueira sem ausência de luz (pico de 794,7 mg. $\mathrm{L}^{-1}$, em $23 \mathrm{~h}$ ), onde a fermentação escura apresentou um acréscimo de $38 \%$ em termos de acúmulo dos ácidos.

Considerando em termos de conversão (Y) de DQO em AGVs, na fermentação com ausência de luz obteve- se $\mathrm{Y}=0,106 \mathrm{mg}$ de $\mathrm{AGV}$ por $\mathrm{mg}$ de DQO, com produtividade $\mathrm{P}=0,005 \mathrm{mg}$ de AGV por mg de DQO por h. Ou seja, comparando com a Tabela 5 isso representa um aumento de 52\% de produtividade para a manipueira com ausência de luz.

Para o permeado do soro do queijo, a fermentação escura apresentou um máximo de acúmulo de AGV de 2391 mg. $\mathrm{L}^{-1}$ em $21 \mathrm{~h}$, e para a mesma fermentação sem ser em ausência de luz, obteve-se um acúmulo de $1986 \mathrm{mg} . \mathrm{L}^{-1}$ em $35 \mathrm{~h}$, onde a fermentação escura apresentou um acréscimo de $20 \%$ de produção de $\mathrm{AGV}$.

Considerando em termos de conversão (Y) de DQO em AGVs, na fermentação com ausência de luz obtevese $\mathrm{Y}=0,016 \mathrm{mg}$ de $\mathrm{AGV}$ por $\mathrm{mg}$ de DQO, com produtividade $\mathrm{P}=0,00076$ $\mathrm{mg}$ de AGV por mg de DQO por h. Comparando com a Tabela 5, isso representa um aumento de $100 \%$ de produtividade para o permeado com ausência de luz.

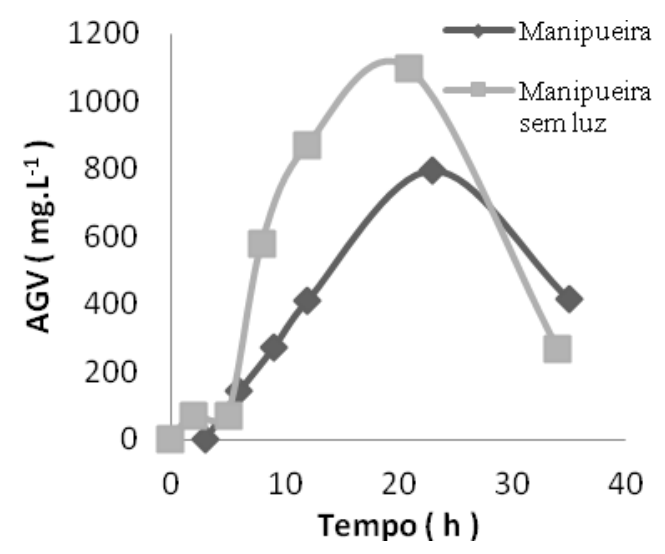

Figura 3 - Comparação do perfil cinético de produção de AGV para a manipueira com e sem ausência de luz. 


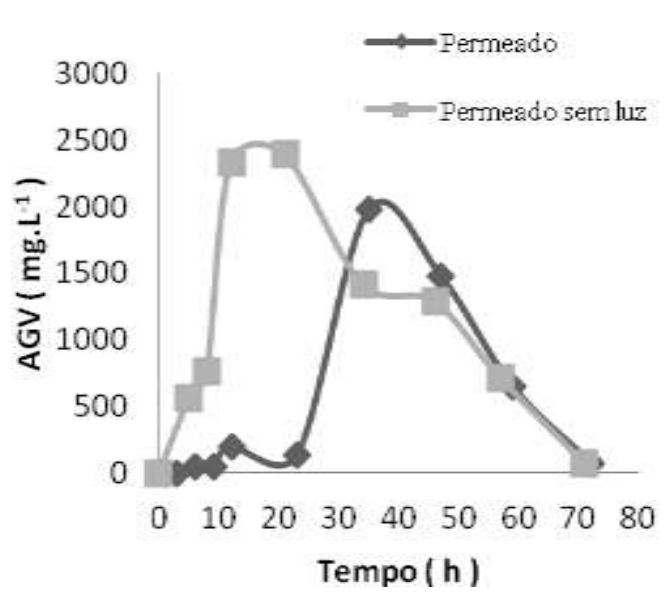

Figura 4 - Comparação do perfil cinético de produção de AGV para o permeado com e sem ausência de luz.

\subsection{INFLUÊNCIA DA GLICOSE E ALCALINIDADE}

\subsubsection{MANIPUEIRA}

Inicialmente serão apresentados os perfis cinéticos de produção de AGVs para os 8 ensaios do planejamento experimental e posteriormente os resultados estatísticos. Os pontos centrais do planejamento (ensaios 5 a 8) que representam as fermentações das repetições apresentaram cinética de acúmulo de AGVs conforme as curvas da Figura 5.

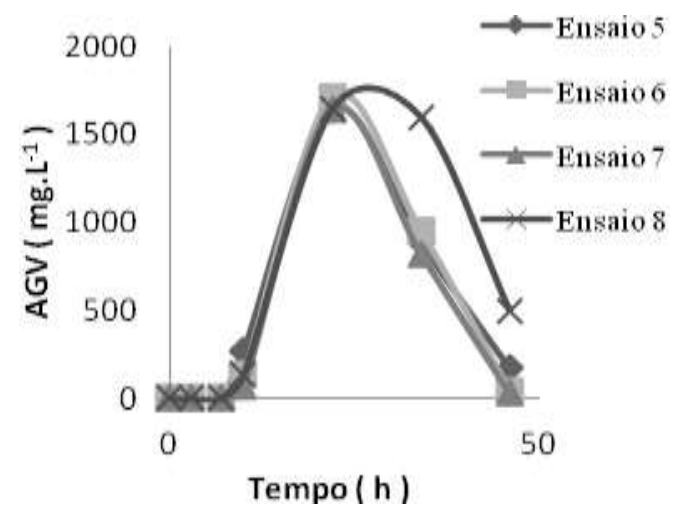

Figura 5 - Perfis cinéticos de produção de AGVs referente a quadruplicata no ponto central do planejamento $2^{2}$, utilizando a manipueira como substrato.

Observa-se que os experimentos foram semelhantes em seu comportamento de produção de $\mathrm{AGV}$, com exceção da replica $\mathrm{n}^{\circ} 8$, de forma que é possível se verificar a reprodutibilidade do processo. As quatro primeiras fermentações do planejamento (ensaios 1 a 4) e também a média da quadruplicata no ponto central apresentaram a cinética de acúmulo de AGVs conforme Figura 6.

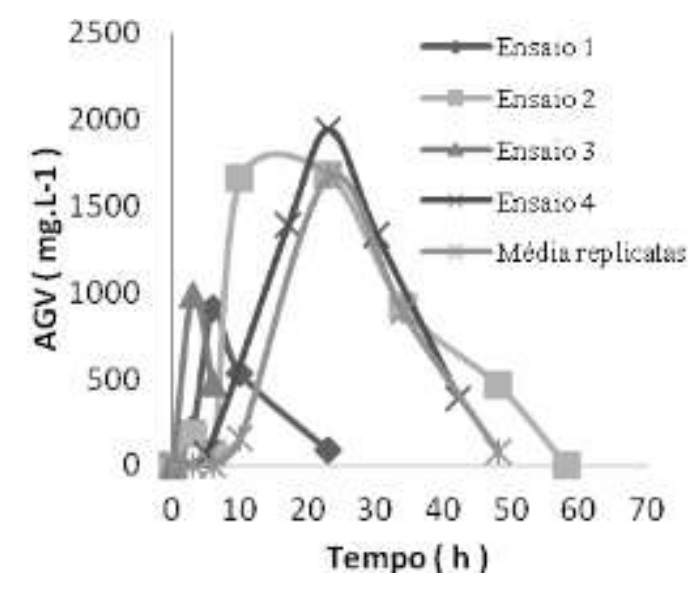

Figura 6 - Perfis cinéticos de produção de AGV referente ao planejamento $2^{2}$, utilizando a manipueira como substrato.

Optou-se então realizar uma quadruplicata da fermentação na melhor condição obtida, referente ao ensaio 4 . Assim, na Figura 7 constam as 4 fermentações nas condições de maior produção de AGVs, afim de se analisar a reprodutibilidade dos experimentos.

Observa-se que as linhas dos experimentos foram muito próximas, significando que o experimento teve reprodutibilidade. A Tabela 6 apresenta a matriz do planejamento, com os resultados obtidos de produção de ácidos graxos voláteis no processo fermentativo.

As concentrações de $29 \mathrm{gL}^{-1}$ de glicose (açúcares redutores ) e 3,21 g.L $\mathrm{L}^{-1}$ de bicarbonato de sódio, foi o que apresentou maior conversão na produção de ácidos graxos voláteis. 


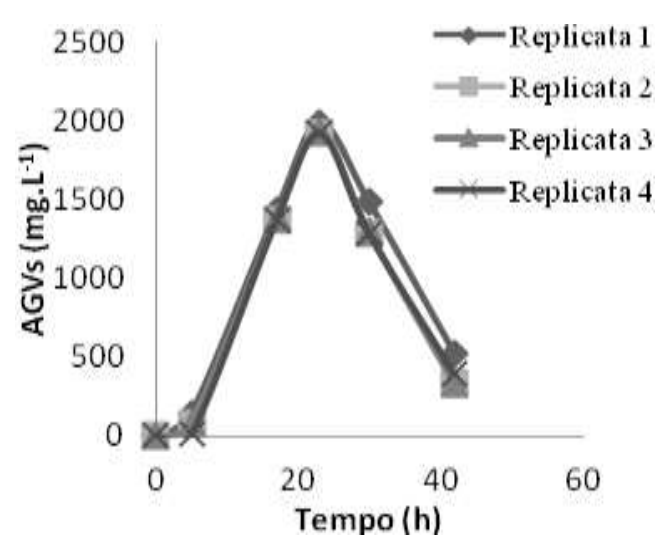

Figura 7 - Perfis cinéticos de produção de AGV referente à quadruplicata do ensaio 4 do planejamento $2^{2}$, utilizando a manipueira como substrato.

Tabela 6 - Resultados de AGV do planejamento fatorial $2^{2}$, utilizando manipueira como substrato

\begin{tabular}{|c|c|c|c|}
\hline Ensaio & $\underset{\left(\mathrm{gaL}^{-1}\right)}{\mathrm{NaHCO}_{3}}$ & $\begin{array}{c}\text { Glicose } \\
\left(\text { g. } L^{-1}\right)\end{array}$ & $\underset{\left(\mathbf{m g} . \mathbf{L}^{-1}\right)}{\mathbf{A G V}}$ \\
\hline 1 & 0,21 & 9 & 912,2 \\
\hline 2 & 3,21 & 9 & 1657,7 \\
\hline 3 & 0,21 & 29 & 985,6 \\
\hline 4 & 3,21 & 29 & 1941,4 \\
\hline 5 & 1,71 & 19 & 1648,5 \\
\hline 6 & 1,71 & 19 & 1648,5 \\
\hline 7 & 1,71 & 19 & 1645,4 \\
\hline 8 & 1,71 & 19 & 1714,1 \\
\hline
\end{tabular}

Realizou-se uma análise estatística dos resultados, onde os ensaios 5 a 8 são as réplicas realizadas no ponto central do experimento. A estimativa dos efeitos principais e de interação das variavéis para o planejamento é apresentada na Tabela 7. Verifica-se que apenas foi significativa a concentração de bicarbonato de sódio, ou seja, influenciou positivamente a produção de ácidos graxos voláteis durante a fermentação (pvalor $=0,0147)$. Tal afirmação é evidenciada na superfície de resposta (Figura 8).
Tabela 7 - Estimativa dos efeitos para a produção de $\mathrm{AGV}$ para o planejamento $2^{2}$ com manipueira $(\alpha=0,05)$

\begin{tabular}{lccc}
\hline Variável & Efeito & $\begin{array}{c}\text { Erro } \\
\text { padrão }\end{array}$ & p - valor \\
$\begin{array}{l}\text { Média/ } \\
\text { Intercepto }\end{array}$ & 1519,18 & 73,191 & 0,000032 \\
$\mathrm{NaHCO}_{3}$ & 850,65 & 207,0115 & 0,014743 \\
$\mathrm{Glicose}$ & 178,55 & 207,015 & 0,437055 \\
$\mathrm{NaHCO}_{3}$ & 105,15 & 207,015 & 0.638228 \\
x Glicose & & & \\
\hline $\mathrm{R}^{2}=81,7 \%$ & & &
\end{tabular}

$\mathrm{Na}$ digestão anaeróbia o $\mathrm{pH}$ é afetado principalmente pela concentração de bicarbonato de sódio, $\mathrm{CO}$ e AGV.

$\mathrm{Na}$ medida em que as bactérias acidogênicas vão produzindo $\mathrm{AGV}, \mathrm{o} \mathrm{pH}$ do sistema vai decrescendo, tornando-o tóxico para as bactérias produtoras de AGVs, de forma que a adição de bicarbonato de sódio contribui para o tamponamento do meio e consequentemente permite maior produção dos ácidos de interesse.

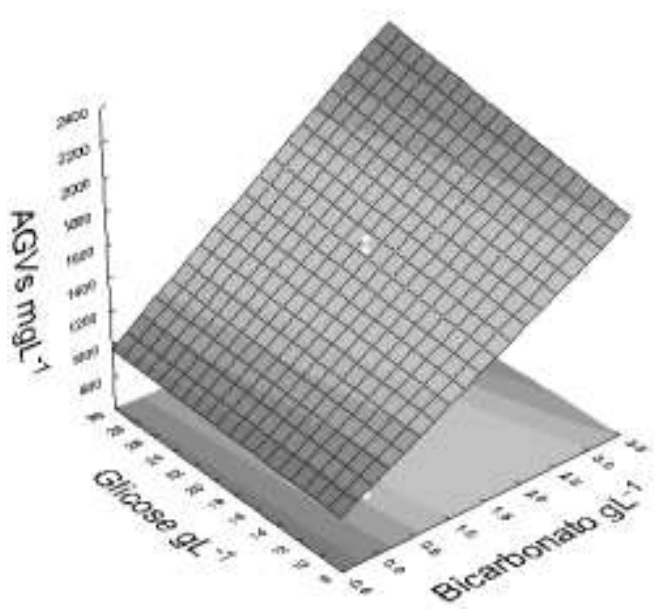

Figura 8 - Superfície de resposta: AGV $\left(\mathrm{mg} . \mathrm{L}^{-1}\right)$ em função da concentração de glicose e do bicarbonato de sódio (g.L

${ }^{1}$ ), para o planejamento $2^{2} \mathrm{com}$ manipueira

Leite et al. (2003), com o objetivo de produzir ácidos graxos voláteis, por biodigestão anaeróbia, utilizaram a manipueira como substrato e argila expandida como suporte para 
imobilização da biomassa, e verificaram que as concentrações obtidas dos ácidos butírico e capróico diminuíram com o aumento da alcalinidade no afluente, enquanto as concentrações do ácido propiônico aumentaram. Foi promovida também uma diminuição do tempo de detenção hidráulica de 2 para 0,5 h o que resultou na diminuição da concentração de ácido butírico, pouco influenciando a produção dos ácidos acético e propiônico. Concluíram ser satisfatória a viabilidade de produção dos ácidos graxos voláteis em função da biodegradabilidade do substrato utilizado.

Os autores afirmam que atingiram concentrações de ácidos butírico e acético de $500 \mathrm{mg} . \mathrm{L}^{-1}$, para um substrato com valor de DQO máximo de $2000 \mathrm{mg} . \mathrm{L}^{-1}$. Giongo (2011) em seus experimentos também concluiu sobre a influencia positiva do bicarbonato de sódio para produção de ácidos graxos voláteis, sendo que as melhores condições foram utilizando a manipueira (DQO de 8865 mg..$^{-1}$ ) como meio de cultivo à $30^{\circ} \mathrm{C}$ com 3,0 g.L. $\mathrm{L}^{-1}$ de bicarbonato de sódio, obtendo-se uma concentração de 3400 mg. $L^{-1}$ de AGV.

Considerando em termos de conversão (Y) de DQO da manipueira em AGVs para o ensaio 4 (Tabela 6) com 1941,4 mg. $\mathrm{L}^{-1}$ de AGVs obtidos com concentração de 29 g.L $L^{-1}$ de açúcares redutores em $21 \mathrm{~h}$, tem-se $\mathrm{Y}=0,067 \mathrm{mg}$ de AGV por $\mathrm{mg}$ de DQO, com produtividade $\mathrm{P}=0,0032 \mathrm{mg}$ de $\mathrm{AGV}$ por $\mathrm{mg}$ de DQO por $\mathrm{h}$. Este valor de produtividade é inferior ao obtido no experimento com ausência de luz ( $\mathrm{P}=$ $0,0050)$ e próximo ao obtido no screening $(\mathrm{P}=$ 0,0033). Entretanto, se for considerado o ensaio 2 (Tabela 6), o mesmo resultou em 1657,7 mg.L ${ }^{-1}$ de AGVs obtidos com concentração de 9 g. $\mathrm{L}^{-1}$ de açúcares redutores com pico de $10 \mathrm{~h}$, o que resulta em $\mathrm{Y}=0,184 \mathrm{mg}$ de $\mathrm{AGV}$ por $\mathrm{mg}$ de DQO, com produtividade $\mathrm{P}=0,0184 \mathrm{mg}$ de $\mathrm{AGV}$ por $\mathrm{mg}$ de DQO por h. Este valor é o mais alto obtido até aqui para a manipueira.

\subsubsection{PERMEADO DE SORO DE QUEIJO}

Foram testados diferentes níveis de concentração de açúcares redutores $\left(50,90\right.$ e 150 g.L $\left.{ }^{-1}\right)$ através da diluição do permeado do soro de queijo que originalmente possui a concentração de 150 g.L $\mathrm{L}^{-1}$ de açúcares redutores. Foram testados também diferentes níveis de alcalinidade em bicarbonato, com a adição de bicarbonato de sódio $(0,0,44$, $1,5,2,56$ e 3,0 g. $\mathrm{L}^{-1}$ ) ao permeado, o qual já continha uma alcalinidade total de 7,7 g.L $\mathrm{L}^{-1}$ em bicarbonato. A concentração final de bicarbonato de sódio foi de 10,26 g. $\mathrm{L}^{-1} \mathrm{em}$ ambos os ensaios, pela adição de 2,56 de $\mathrm{NaHCO}_{3}$.

Nota-se (Figura 9) que os picos de AGVs foram próximos apesar da grande variação de (açúcares redutores) no meio. Para a fermentação com a concentração de 90 g. $\mathrm{L}^{-1}$ houve o pico de 4115,16 mg. $L^{-1}$ de AGVs em 41 h, e para a fermentação com a concentração de 150 g. $L^{-1}$ de açúcar redutor houve o pico de 3928,54 mg.L L $^{-1}$ de AGVs em 29 h. Uma possível explicação para o retardo verificado na produção de $\mathrm{AGV}$ com permeado na concentração de açúcar redutor de 90 g. $\mathrm{L}^{-1}$ talvez se deva a uma restrição em termos de difusão do processo uma vez que o fluxo molar do nutriente (açúcar) à célula é proporcional ao gradiente de concentração do nutriente. 


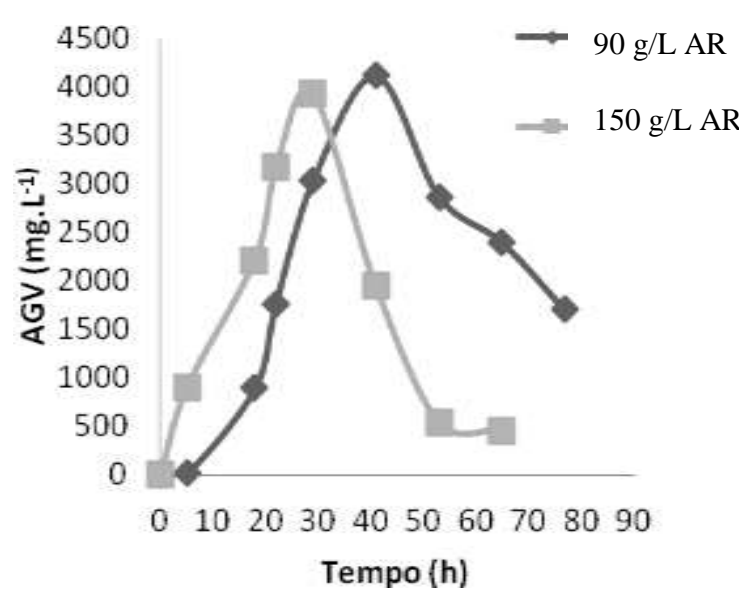

Figura 9 - Perfis cinéticos de AGVs utilizando o permeado de soro de queijo como substrato, e concentrações de glicose de 90 g.L $L^{-1}$ (diluído) e 150 g.L - $^{-1}$ (puro) e 10,26 g.L $\mathrm{L}^{-1}$ de bicarbonato de sódio.

Posteriormente foram testadas para a concentração de 90 g.L. L $^{-1}$ de açúcares redutores no permeado, duas concentrações de bicarbonato de sódio $\left(8,14\right.$ e 10,26 g.L $\left.{ }^{-1}\right)$ com a adição de 0,44 e 2,56 g. $\mathrm{L}^{-1}$ de $\mathrm{NaHCO}_{3}$, respectivamente (Figura 10).

Nota-se maior produção de AGVs para a fermentação que possuía maior concentração de alcalinidade. O pico para a concentração de 8,14 g.L - $^{-1}$ de alcalinidade foi de $3566,75 \mathrm{mg} . \mathrm{L}^{-1}$ de AGV em $41 \mathrm{~h}$. O pico para a concentração de 10,26 g. $L^{-1}$ foi de 4115,16 de AGVs em 41 h. Assim, obteve-se um acréscimo de $15,4 \%$ na produção de AGVs.

$\mathrm{O}$ efeito positivo do bicarbonato de sódio (alcalinidade) na produção de AGVs foi evidenciado também para as fermentações utilizando manipueira como substrato, como já mencionado anteriormente. Norton et al. (1994) em seus estudos utilizaram uma base fraca, hidróxido de amônio, para tamponamento do meio e controle de $\mathrm{pH}$, de forma a obter a produção de ácido lático, utilizando o permeado de soro de queijo como substrato para a fermentação e Lactobacillus helveticus imobilizado, e obtiveram estabilidade do meio em relação ao $\mathrm{pH}$, atingindo produção de $28,5 \mathrm{~g} \cdot \mathrm{L}^{-1} \cdot \mathrm{h}^{-1}$ de ácido lático.

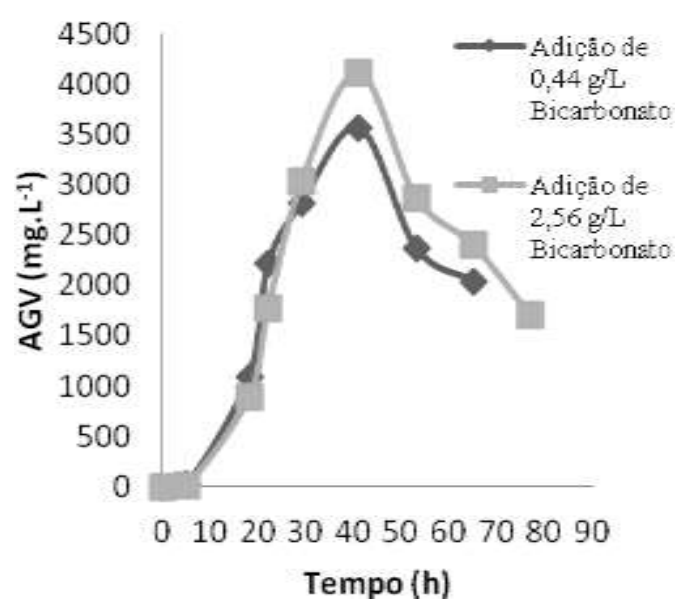

Figura 10 - Perfis cinéticos de AGVs utilizando o permeado de soro de queijo como substrato, concentrações finais de bicarbonato de sódio de 8,14 g.L $\mathrm{L}^{-1} \mathrm{e}$ 10,26 g.L. ${ }^{-1}$ e $90 \mathrm{~g} . \mathrm{L}^{-1}$ de açúcares redutores.

Para o teste das concentrações de açúcares redutores, os picos foram bem próximos (Figura 9). Assim, decidiu-se testar as concentrações de bicarbonato de sódio com o efluente bruto, como recebido da empresa, ou seja, 150 g.. $\mathrm{L}^{-1}$ de açúcares redutores.

Na Figura 11, estão os resultados das fermentações utilizando o permeado na concentração de origem, 150 g. $\mathrm{L}^{-1}$ de açúcares redutores, variando a concentração de bicarbonato de sódio adicionadas ao meio de 0 a 3 g.L $L^{-1}$.

Nota-se que sem a adição de bicarbonato de sódio (alcalinidade original do permeado de 7,7 g.L $\mathrm{L}^{-1} \mathrm{em}$ bicarbonato) obteve-se a menor concentração de AGV, de 3526,27 mg.. $\mathrm{L}^{-1}$ em $29 \mathrm{~h}$. Com as adições das concentrações de 0,44 g.L. $L^{-1}$ e 3 g.L. $L^{-1}$ de bicarbonato de sódio, resultando em concentrações finais de 8,14 e 10,7 g.L. ${ }^{-1}$ de $\mathrm{NaHCO}_{3}$, respectivamente, atingiram níveis bem próximos entre si, e superiores em relação a concentração de 7,7 g.L $\mathrm{L}^{-1,}$ sendo o pico de produção de 3554 mg.L-1 de AGVs em $22 \mathrm{~h}$ para a concentração de 8,14 g. $\mathrm{L}^{-1}$ de alcalinidade em bicarbonato e pico de 3588,32 mg. $\mathrm{L}^{-1}$ de AGVs em 41h para 10,7 g.L ${ }^{-1}$ Nota-se que o para concentrações maiores de bicarbonato de 
sódio, o pico de produção de $\mathrm{AGV}$ s é retardado, acredita-se que seja devido ao tamponamento.

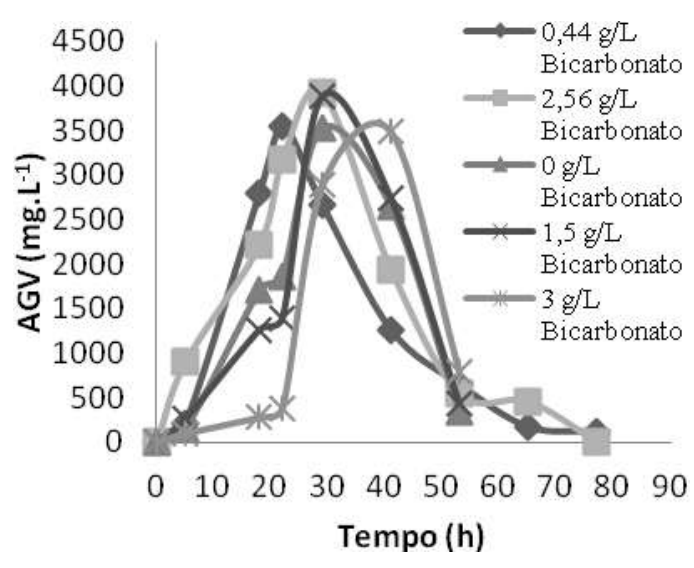

Figura 11 - Perfis cinéticos de AGVs utilizando o permeado de soro de queijo como substrato, diferentes concentrações de bicarbonato de sódio e 150 g.L $\mathrm{L}^{-1} \mathrm{de}$ açúcares redutores.

Os maiores picos de produção de AGV ocorreram nas adições de concentrações de 1,5 e 2,56 g. $L^{-1}$ de bicarbonato de sódio, resultando em uma concentrações finais de 9,2 e 10,26 g.L. $\mathrm{L}^{-1}$ de $\mathrm{NaHCO}_{3}$. O pico de produção para a concentração de 9,2 g. $\mathrm{L}^{-1}$ foi de 3891,52 $\mathrm{mg} . \mathrm{L}^{-1}$ de $\mathrm{AGVs}$ em $29 \mathrm{~h}$ e o pico de produção para a concentração de 10,26 g. $\mathrm{L}^{-1}$ foi de $3928,54 \mathrm{mg} . \mathrm{L}^{-1}$ de AGVs em 29h, sendo válido ressaltar que a concentração de açúcares redutores utilizada foi de 150 g.L L $^{-1}$. Dessa forma, é preferível efetuar os experimentos com a adição de concentração de 1,5 g. $\mathrm{L}^{-1}$ de bicarbonato de sódio, uma vez que os dois picos foram bem próximos tendo havido pouca diferença na produção de AGV com o acréscimo de bicarbonato de sódio.

Ao observar a Figura 9, verificase que, diminuindo a concentração de açúcares redutores no permeado do soro de queijo de 150 para 90 g. $\mathrm{L}^{-1}$ resultou em um pequeno acréscimo na produção de AGVs. Assim, foi testada uma nova diluição do permeado do soro de queijo, atingindo-se a concentração de 50 g. $\mathrm{L}^{-1}$ de açúcares redutores, e fixando-se a concentração final de bicarbonato de sódio em 9,2 g.L ${ }^{-1}$ de $\mathrm{NaHCO}_{3}$, os resultados obtidos estão na Figura 12.
Embora a diminuição da concentração de 150 g.L $L^{-1}$ de açúcares redutores para $90 \mathrm{~g} . \mathrm{L}^{-1}$ tenha sido positiva (Figura 9), a diminuição de 150 g.L $\mathrm{L}^{-1}$ de açúcares redutores para 50 g. $\mathrm{L}^{-1}$ não foi. Para a maior concentração de açúcar, obteve-se um pico de $3891,58 \mathrm{mg} . \mathrm{L}^{-1} \mathrm{em}$ $29 \mathrm{~h}$, e para a menor concentração, o pico de produção foi de $2769,47 \mathrm{mg} . \mathrm{L}^{-1}$, também em $29 \mathrm{~h}$, chegando a ser menor que o pico de concentração obtido pela fermentação feita com 150 g.L. $\mathrm{L}^{-1}$ de açúcares redutores e 7,7 g. $\mathrm{L}^{-1}$ de bicarbonato de sódio $\left(3526,27 \mathrm{mg} . \mathrm{L}^{-1} \mathrm{de}\right.$ AGVs em 29 h).

Por fim, decidiu-se testar a reprodutibilidade dos experimentos, fazendo uma triplicata da fermentação cujas condições de operação proporcionaram maior pico de produção de AGVs. Tais condições de operação foram 90 g. $\mathrm{L}^{-1}$ de açúcares redutores e 9,2 g. $\mathrm{L}^{-1}$ de $\mathrm{NaHCO}_{3}$ (Figura 13). Nota-se que, os picos foram próximos. Para a replicata 1, o pico de produção foi de 4074,73 mg. $\mathrm{L}^{-1}$ de AGVs, para a replicata 2, o pico de produção foi de $4006 \mathrm{mg}$. $\mathrm{L}^{-1}$ de AGVs, e para a replicata 3, o pico de produção foi de 4001,4 mg. $\mathrm{L}^{-1}$ de AGVs, todos em $41 \mathrm{~h}$, sendo a média aritmética 4027,38 mg. $\mathrm{L}^{-1}$ de AGVs.

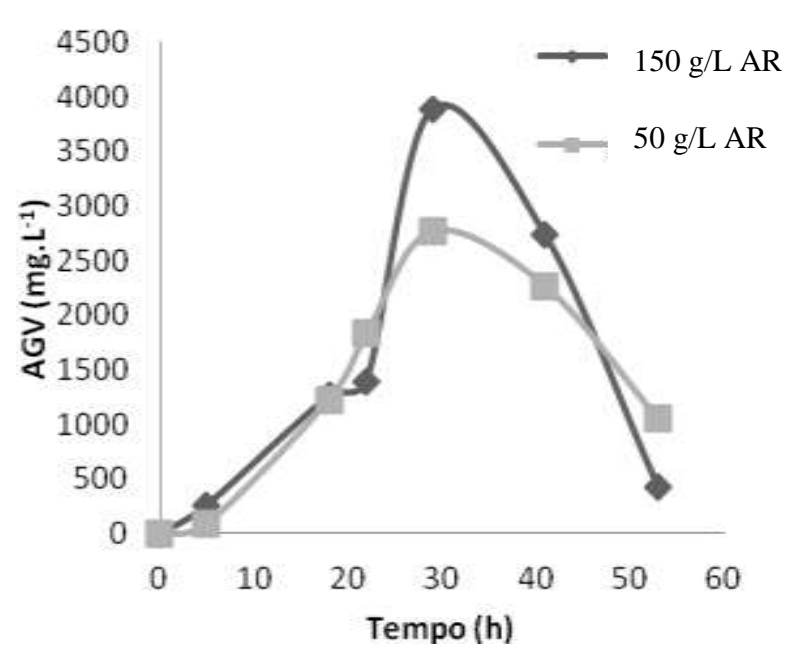

Figura 12 - Perfis cinéticos de AGVs utilizando o permeado de soro de queijo como substrato, concentrações de açúcares redutores de 50 e 150 g.L $L^{-1}$ e 9,2 g. $\mathrm{L}^{-1}$ de alcalinidade. 
Assim, o maior pico atingido com a utilização do permeado foi de 4115,16 mg.L $L^{-1}$ de AGVs, com 90 g.L. $L^{-1}$ de açúcares redutores e adição de 1,5 g.L ${ }^{-1}$ de bicarbonato de sódio $\left(9,2\right.$ g. $\mathrm{L}^{-1}$ de concentração final de $\mathrm{NaHCO}_{3}$ ) (Figura 13) embora este valor seja muito próximo com o atingido usando o permeado de soro de queijo bruto (150 g.L $\mathrm{L}^{-1}$ de açúcares redutores) e com a concentração de 9,2 g.L $\mathrm{L}^{-1}$ de $\mathrm{NaHCO}_{3}$.

O maior pico de AGVs utilizando o permeado de soro de queijo como meio de cultivo $\left(4115,16 \mathrm{mg} . \mathrm{L}^{-1}\right)$ foi superior em $112 \%$ ao maior maior pico de AGVs utilizando a manipueira como meio de cultivo (1941,4 mg. $\left.\mathrm{L}^{-1}\right)$. Considerando em termos de conversão (Y) de DQO do permeado em AGVs com 4115,16 mg.L $\mathrm{L}^{-1}$ de AGVs obtidos com concentração de 90 g. $\mathrm{L}^{-1}$ de açúcares redutores em $41 \mathrm{~h}$, tem-se $\mathrm{Y}=0,0457 \mathrm{mg}$ de $\mathrm{AGV}$ por $\mathrm{mg}$ de DQO, com produtividade $\mathrm{P}=0,0011$ mg de AGV por mg de DQO por h. Este valor de produtividade é superior ao obtido no experimento com ausência de luz $(\mathrm{P}=0,000764)$ e superior ao obtido no screening $(\mathrm{P}=0,00038)$, para $\mathrm{O}$ permeado. Entretanto, resultou menor que a produtividade da manipueira que foi de $\mathrm{P}=0,0184 \mathrm{mg}$ de $\mathrm{AGV}$ por $\mathrm{mg}$ de DQO por h.

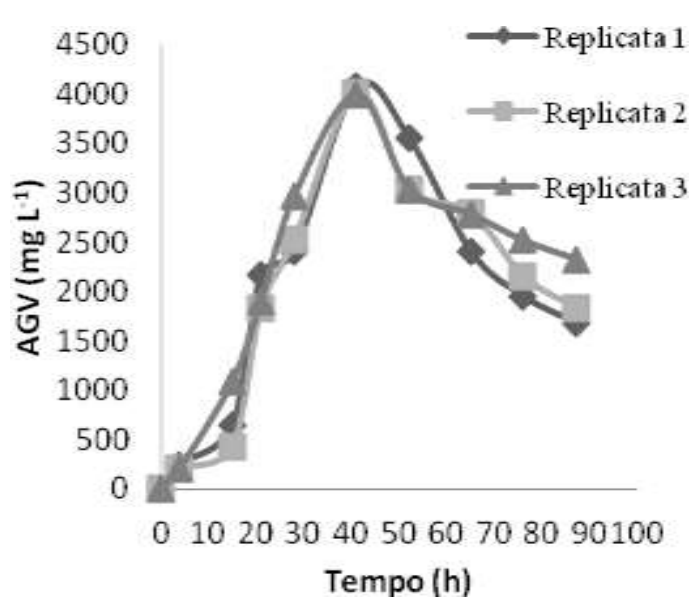

Figura 2 - Triplicata de perfis cinéticos de AGVs utilizando o permeado de soro de queijo como substrato, 90 g. $\mathrm{L}^{-1}$ de açúcares redutores e 9,2 g. $\mathrm{L}^{-1}$ de $\mathrm{NaHCO}_{3}$.

\section{CONCLUSÕES}

Nos experimentos realizados com o intuito de avaliar o melhor resíduo como substrato para a produção de AGVs, destacam-se a manipueira e o permeado do soro de queijo. Obteve-se elevação no acúmulo de AGV quando os experimentos foram realizados na ausência de luz, sendo os demais parâmetros mantidos. $\mathrm{O}$ acréscimo no acumulo foi de $49 \%$ para a fermentação utilizando a manipueira e $100 \%$ utilizando o permeado do soro do queijo. Foi evidente o aumento na produção de AGV com a utilização da manipueira, com determinados níveis de concentração de açúcares redutores e bicarbonato de sódio do planejamento experimental. $\mathrm{O}$ maior valor observado de produtividade para a manipueira foi $\mathrm{P}=0,0184 \mathrm{mg}$ AGV por mg de DQO por h, representando um acréscimo de $460 \%$ quando comparado a fermentação com a manipueira (screening) antes de se efetuar os experimentos do planejamento experimental.

Para os testes realizados utilizando o permeado de soro de queijo como substrato, concluiu-se que, dentre as concentrações de alcalinidade e açúcares redutores, as condições de operação que apresentaram melhor produção de AGVs foram 90 g.L $\mathrm{L}^{-1}$ de açúcares redutores e 10,26 g.L $\mathrm{L}^{-1}$ de alcalinidade em bicarbonato (4115,16 mg. $\mathrm{L}^{-1}$ de AGVs em 41 h), com produtividade $\mathrm{P}=0,0011 \mathrm{mg}$ de $\mathrm{AGV}$ por mg de DQO por h.

O meio de cultivo com manipueira foi o que resultou em maior conversão de DQO em AGVs, com maior nível de produtividade. Os picos de concentrações de AGVs atingidos foram satisfatórios, evidenciando o uso da manipueira e também do permeado de soro de queijo no processo de biodigestão anaeróbica. 


\section{AGRADECIMENTOS}

Os autores agradecem à Capes pelo apoio financeiro.

\section{REFERÊNCIAS}

APHA, AWAA AND WEF. Standard Methods for Examination of Water and Wastewater., American Publications Health Association. 19th ed., Washington D. C., 1998.

BARANA, A. C.; CEREDA, M. P. Cassava wastewater (manipueira) treatment using a two phase anaerobic biodigestor. Ciência e Tecnologia de Alimentos, v. 20, n. 2, 2000.

BRABER, K. 1995. Anaerobic digestion of municipal solid waste: a modern waste disposal option on the verge of breakthrough. Biomass and Bioenergy. v. 9, p. 365-376.

Brasil. Instrução Normativa $\mathrm{N}^{\circ} 68$ de 12 de dezembro de 2006. Métodos analíticos oficiais físico-químicos para controle de leite e produtos lácteos. Ministério da Agricultura Pecuária e Abastecimento, DF. Disponível em <http://www.agricultura.gov.br>. Acesso em 17/07/2012.

BRAUN, R., DROSG, B., BOCHMANN, G., WEIF, S., KIRCHMAYR, R. 2010. Microbes at work Alemanha, Berlin: Springer-verlag. Capitulo 2: Recent developments in bioenergy recovery through fermentation. $1^{\text {st }}$ Edition. v. 8 p 20-25.

BRONSTEIN, V.; ALEGRE, R. M. 1998. Estudos dos parâmetros da ultrafiltração de permeado de soro de queijo fermentado por Lactococcuslactis subsp. lactis. Ciência e Tecnologia de Alimentos. v.18, n. 1.

BUCHAUER, K. 1998. Comparison of two simple titration procedures to determine volatile fatty acids in influents to waste-water and sludge treatment processes. Water SA. v. 24, n. 1.
CAMPOS, J. R. Alternativas para tratamentos de esgotos: pré-tratamento de águas de abastecimento. Americana: Consórcio Intermunicipal das Bacias dos rios Piracicaba e Capivari, 112p., 1994.

CEREDA, M. P. Manejo, uso e tratamento de subprodutos da industrialização da mandioca. São Paulo: Fundação Cargill. 2001. Capítulo 1: Caracterização dos subprodutos da indústria da mandioca, v.4, p 13-37.

CEREDA, M. P.; MATTOS, M.C.Y. Linamarin: The Toxic Compound Of Cassava. Journal of Venomous Animals and Toxins, Botucatu, v.2, n.1, 1996. Disponível em: $<$ http://www.scielo.br/scielo.php?script=s ci_arttext\&pid=S0104-

$79301996000100002 \& \operatorname{lng}=\mathrm{en} \& \mathrm{nrm}=\mathrm{iso}>$ . Acesso: 19/01/2012.

CORREIA, G. T.; DEL BIANCHI, V. L. Tratamento biológico de água residuária da produção de farinha de mandioca utilizando reator anaeróbico compartimentado vertical (RACOV). Semina: Ciências Exatas e da Terra, v. 29, n. 2, p. 159-166, 2008.

FERNANDÉZ-MORALES, F. J.; VILLASEÑOR, J.; INFANTES, D. Modeling and monitoring of the acclimatization of conventional activated sludge to a biohydrogen producing culture by biokinetic control. International Jounal of Hydrogen Energy, v.35, p. 10927-10933, 2010.

GIONGO, C. 2011. Produção de ácidos graxos voláteis por biodigestão anaeróbia da manipueira. Dissertação de Mestrado, Universidade Estadual do Oeste do Paraná.

INCE, O.; ANDERSON, G. K.; KASAPGIL, B. Control of organic loading rate using the specific methanogenic activity test during star-up of an anaerobic digestion system. Water Research, v. 29, n. 1, p. 349-55, 1995.

Instituto Adolfo Lutz. Normas Analíticas do Instituto Adolfo Lutz. v. 1: Métodos 
químicos e físicos para análise de alimentos, 3. ed. São Paulo: IMESP, 1985, p. 25-26.

KRUEGER, C. L. 2009. Seleção de linhagens de bacillus produtoras de polihidroxialcanoatos a partir de resíduo. Dissertação de Mestrado, Universidade Federal de Santa Catarina.

LAMAISON, F. DO C. 2009. Aplicação da água residuária do processamento da mandioca como substrato para a produção de hidrogênio por processo fermentativo. Dissertação de Mestrado, Universidade Federal de Santa Catarina.

LEE, W.S.; CHUA, A.S.M.; YEOH, H.K.; NGOH, G.C. A review of the production and applications of wastederived volatile fatty acids. Chemical Engineering Journal, v. 235, p. 83-99, 2014.

LEITE, J. A. C.; FORESTI, E.; BARBOZA, M.; ZAIAT, M. Produção de ácidos graxos voláteis por fermentação acidogênica em reator anaeróbio horizontal de leito fixo com argila expandida como suporte da biomassa. In: Simpósio Nacional de Fermentações, 14, 2003, Santa Catarina. Anais. Disponível em: $<w w w . e n q . u f s c . b r / e v e n t o s / s i n a f e r m / t$ rabalhos_completos/t121.doc>, Acesso: $29 / 04 / 2012$

LEONEL, M. MANEJO. Uso e tratamento de subprodutos da industrialização da mandioca. São Paulo: Fundação Cargill, 2001. Cap. 18: Uso dos subprodutos da industrialização da mandioca na alimentação animal., v.4, p. 229-239.

LOSS, R. A. 2011. Avaliação da Produção de Hidrogênio por Consórcio Bacteriano Foto heterotrófico. Dissertação de Mestrado, Universidade Federal de Santa Catarina.

MACKERETH, F. J. H.; HERON, J.; TALLING, J. F. Water analysis: some revised methods for limnologists. Freshwater Biology, v. 36, p. 1-121, 1978.
MAHAN, K. L. Alimentos, Nutrição \& Dietoterapia, $9^{a}$ edição, São Paulo: Roca, 1998.

MILLER, G.L. Use of dinitrosalicylic acid reagent for determination of reducing sugars. Anal. Chem., v. 31, p. 426-428, 1959.

MOHAN, S.V.; BABU, V.L.; SARMA, P.N. Anaerobic biohydrogen production from dairy wastewater treatment in sequencing batch reactor: effect of organic loading rate. Enzime and Microbial Technology. v. 24, p. 506-515, 2007.

NORTON, S.; LACROIX, C.; VUILLEMARD, J. C. Kinetic Study oh Continuous Whey Permeate Fermentation by Immobilized Lactobacillus helveticus for Latic Acid Production. Canadá: Butterworth-Heinermann. Enzyme Microb. Technol., v. 16, 1994.

OLIVEIRA, K. R. F. Processos ecotecnológicos no tratamento de efluentes líquidos de fecularia. Mato Grosso do Sul, Tecnologias Ambientais, Universidade Federal de Mato Grosso do Sul, 2007. 97p. Dissertação (Mestrado).

OLIVEIRA, M. C. L.; MOURA, J. P.; BENEDEL, H. D. Caracterização química e Avaliação sensorial de Bebida Hidroeletrolítica Fermentada Obtida a Partir de Permeado de Leite Tipo C. Revista Analítica, n. 23, p. 78-83, 2006.

PASTORE, N. S. 2010. Avaliação de diferentes fontes de nitrogênio e sacarose na produção de ácido cítrico por Aspergillus niger usando manipueira como substrato. Dissertação de Mestrado, Universidade Estadual do Oeste do Paraná.

STEIL, L. 2001. Avaliação do uso de inóculos na digestão anaeróbia de resíduos de aves de postura, frangos de corte e suínos. Dissertação de Mestrado , Universidade Estadual Paulista.

SUN, L.; WANB, S.; YU, Z.; WANGA, Y.; WANG, S. Anaerobic biological 
treatment of high strength cassava starch wastewater in a new type up-flow multistage anaerobic reactor. Bioresource Technology, v. 104, p. 280-288, 2012. 